\title{
Gestor Júnior: plataforma de gestão de projetos para a Designeria Empresa Júnior
}

\author{
Gestor Júnior: project \\ management platform for \\ Designeria Empresa Júnior
}

Júlia Lima da Silva ${ }^{[1]}$, Helena de Araújo Neves ${ }^{[2]}$

\begin{abstract}
Resumo: Este artigo trata-se de um recorte de uma pesquisa que resultou na criação da plataforma Gestor Júnior - visando gerir os projetos da Designeria - Empresa Júnior vinculada aos cursos de Design da UFPel. Em tal investigação buscou-se debater os conceitos da Gestão e do Design a partir dos estudos de Mozota (2011) e Best (2012). A partir dessas perspectivas, investigou-se o sistema de funcionamento da referida Empresa utilizando-se, como técnicas de coleta de dados, de análise de documentos; de questionário aplicado nos ex-integrantes da empresa e de análise de concorrentes. Como resultado, neste artigo é exposto o desenvolvimento da plataforma projetada para tal Empresa Júnior, mas que tem potencial para ser aplicada em outras Empresas a partir da metodologia de projeto de Garrett (2011), com potencial para ser escalável.
\end{abstract}

Palavras-chave: Gestão do Design. Gestão de Projetos. Empresajúnior. Designeria.

Abstract: This article is an excerpt from a research that resulted in the creation of the Junior Manager platform - aiming to manage the projects of Designeria - Junior Company linked to UFPel's Design courses. In this investigation, we sought to debate the concepts of Management and Design from the studies of Mozota (2011) and Best (2012). From these perspectives, the company's operating system was investigated using, as data collection techniques, document analysis; questionnaire applied to

[1] Bacharel em Design Gráfico, UFPEL. julialima.design@gmail.com

[2] Doutorado em Educação, UFPEL.profhelena.neves@gmail.com 
former members of the company and analysis of competitors. As a result, this article exposes the development of the platform designed for such a Junior Company, but which has the potential to be applied in other Companies based on Garrett's (2011) project methodology, with the potential to be scalable.

Keywords: Design Management. Project management. Junior company. Designeria.

\section{INTRODUÇÃO}

O presente artigo tem como objetivo evidenciar um recorte dos resultados obtidos através da prática projetual oriunda de um Trabalho de Conclusão de Curso. Este foi desenvolvido junto ao curso de Design Digital da Universidade Federal de Pelotas, além de apresentado e defendido ao final do segundo semestre de 2019. Tal investigação buscou, por meio de uma revisão documental e bibliográfica, pleitear a relação entre a Gestão e o Design voltados para o processo de gerenciamento de projetos realizado pela Designeria Empresa Júnior - a Empresa Júnior dos cursos de Design da UFPEL. O principal propósito da pesquisa foi desenvolver um protótipo de plataforma, formato web, de Gestão de Projetos alinhada às necessidades da Designeria - e de uso dos principais gestores da empresa.

A Designeria foi escolhida como objeto de estudo, porque além da autora da pesquisa ser uma de suas integrantes e ter contato direto com a prática cotidiana, percebeu ainda que é incomum o acesso de conteúdos sobre Gestão e Design aplicados a empresas juniores. Sendo assim, ao analisar a relação entre Gestão e Design com a história e as práticas da Designeria, tendo por base uma revisão documental acerca de processos de gerenciamento de projetos e através de estudos de caso de trabalhos realizados pela empresa, tal integrante visualizou a necessidade e a potencialidade de articular os preceitos da gestão junto a uma empresa de pequeno porte. Ainda com relação à metodologia científica e de projeto, foi realizado um benchmarking com duas plataformas de gestão de projetos, sendo elas a plataforma Operand ${ }^{[3]}$ e o Trello[4] - esta foi utilizada pela empresa em gestões passadas,

[3] Para mais ler: SILVA, (2019). [4] Para mais ler: SILVA, (2019). 
porém não houve a continuidade de seu uso. Ao verificar outras plataformas a intenção foi identificar as melhores práticas do mercado e definir as funcionalidades que seriam mais relevantes para o cenário estudado. Também foi aplicado um questionário aberto em ex-integrantes da empresa, com o intuito de auxiliar a coleta de informações para embasar as definições presentes na prática projetual resultante da investigação. $O$ objetivo foi o de que membros da equipe pudessem expor suas percepções sobre pontos importantes que deveriam ser contidos na ferramenta projetada.

Dessa forma, definiu-se que o objetivo geral da referida pesquisa que originou este artigo fosse desenvolver um protótipo de uma plataforma, formato web, de Gestão de Projetos alinhada às necessidades da Designeria. Para atingir tal intenção, os objetivos específicos estipulados foram: a) Entender como se dá a relação entre Gestão e Design, com enfoque na área de gerenciamento de projetos; b) Estudar o processo de formação da Designeria, analisando sua estrutura empresarial, elucidando o procedimento de recebimento de uma solicitação de trabalho passando por sua concepção e chegando em sua entrega; c) Fazer um benchmarking de plataformas de gestão de projetos a fim de localizar as melhores práticas de mercado para a área; d) Projetar uma interface/protótipo para auxiliar no gerenciamento de trabalhos da Designeria Empresa Júnior com base na metodologia de Garrett (2011).

Levando em consideração as percepções que estimularam a pesquisa, foram discutidas as perspectivas de Gestão e do Design investigadas por meio de Best (2012), Mozota (2011) e PMI (2013). A investigação também abordou a história da Designeria expondo as rotinas de processos da Empresa Júnior a fim de compreender quais eram as reais necessidades para realizar uma gestão mais assertiva e otimizada de seus projetos. Buscou-se entender, ainda, como uma ferramenta no cenário digital poderia atender aos anseios de uma equipe de designers júniores. Em linhas gerais, o objetivo foi propor uma ferramenta para uso interno da empresa que 
possibilitasse uma experiência centrada nas necessidades das pessoas que ali trabalhavam, utilizando a Designeria Empresa Júnior como objeto de pesquisa.

Com este artigo, contudo, pretende-se expor parte do resultado da prática projetual resultante da pesquisa - a partir da apresentação da construção de um fluxo da plataforma denominada Gestor Júnior.

\section{GESTÃO E DESIGN}

Para que fosse possível compreender como se dá a relação das áreas de Gestão e do Design foram trabalhados conceitos e indagações introdutórias sobre o assunto, tais como: O que é Gestão? O que é Design? A partir disso, foi possível identificar os pontos de contato entre as duas áreas (SILVA, 2019).

O conceito de Gestão é amplamente debatido e até os dias atuais ainda não se chegou em uma definição universal. Uma das definições clássicas da gestão é a de que essa tem a responsabilidade de organizar sistemas e processos, tornando-se fundamental para o funcionamento das organizações. Para Best (2012, p.13), "o termo gestão refere-se às pessoas e processos envolvidos no gerenciamento, na organização, no controle e na administração de uma empresa". Para Luft (2001, p.352), a Gestão define-se como "ação ou efeito de gerir; gerência; administração". A partir dos conceitos apresentados, percebe-se que Best (2012) considera o sujeito ativo em sua perspectiva - enquanto Luft (2001) dá enfoque para o processo, não incluindo o sujeito em sua definição. Como esta pesquisa foi desenvolvida por uma graduanda na área do Design, acabou por definir que a conceituação de Best (2012) seria a mais consistente para a área de pesquisa e da área de atuação da Empresa Júnior objeto de sua pesquisa, pois inclui o fator humano: algo que é imprescindível para o campo do Design.

O conceito de Design assim como o de Gestão, também é bastante debatido no meio acadêmico e pode ser compreendido através de seus aspectos práticos, ergonômicos e estéti- 
cos, priorizando as necessidades humanas e visando sempre à qualidade de vida para seus usuários. Por isso, apresenta-se a definição de Best (2012, p.12), quando essa afirma que: "o design é um processo de resolução de problemas centrado nas pessoas". Para Mozota (2011, p.16), por sua vez, o "Design é o fator central da humanização inovadora de tecnologias e o fator crucial do intercâmbio cultural e econômico. A intenção com esta breve explanação é desmitificar o Design como sendo um campo relacionado apenas à estética, já que o mesmo não se limita somente à aparência. Isso porque o Design também busca avaliar e idealizar as relações estruturais, organizacionais, funcionais e econômicas.

O design é uma atividade que envolve um amplo espectro de profissões, o que engloba produtos, serviços e sistemas gráficos, interiores e arquitetura. A vantagem dessa definição é que ela evita a armadilha de ver o design somente a partir do resultado (estética e aparência). [...] Os designers são especialistas que refinaram a habilidade de conceber forma e possuem conhecimento multidisciplinar (MOZOTA, 2011, p.16).

Por isso, cada vez mais as organizações estão tomando ciência de que o Design pode ser o fator de transformação no meio dos negócios. Para Best (2012, p.12) “as empresas precisam conhecer os processos e práticas de design específicos e interdisciplinares, bem como seu potencial para fomentar mudanças".

Como a empresa o foco da investigação que se expõe neste artigo atua na área de Design, partiu-se do princípio de que seus integrantes estão familiarizados com as possibilidades do campo, quais sejam: organização, sistematização e metodologias. Contudo, como a pesquisadora faz parte dessa equipe de trabalho, percebeu que tal empresa precisava de uma ferramenta de gestão que potencializasse seus processos e aproximasse sua equipe. Sendo assim, a partir dos conceitos teóricos investigados e por meio da vivência junto à Empresa Júnior de Design dos cursos de Design da UFPel, foi possível identificar e enfocar o Design sob uma perspecti- 
va gerencial. Sendo assim, percebe-se que a Gestão, quando atrelada ao Design como área criativa, pode tornar-se menos inflexível, buscando sempre envolver o indivíduo nos processos e fazendo com que o mesmo trabalhe sua independência, tornando-o proativo para com suas responsabilidades.

A gestão do design está diretamente relacionada ao processo de mudança de um modelo de administração taylorista, hierárquico, para um modelo organizacional plano e flexível, que incentiva a iniciativa individual, a independência e a tomada de risco. Os designers sentem-se à vontade com o novo modelo de gestão mais informal (MOZOTA, 2011, p.91).

Para compreender como funciona o processo de gerenciamento através do Design, torna-se necessário entendê-lo como uma ferramenta que agrega valor. Junto às empresas o Design tem a capacidade, dentre tantas outras funções, de posicioná-las, definir seu público-alvo e diferenciá-las no mercado. Segundo Anders (2000, apud MOZOTA, 2011, P.30) " o processo de design é um processo de identidade, ela define a empresa, seus clientes e investidores". Ao conceituar os termos Gestão e Design, além de elucidar o ponto de contato entre as duas áreas foi necessário debater a Gestão de Projeto para uma real aproximação com o objeto da investigação.

Para entender a Gestão de Projetos foi preciso compreender que a mesma envolve conhecimentos a saber, tais como: o que é um projeto, o que é equipe e o que é processo. $\mathrm{Na}$ pesquisa realizada os conceitos foram debatidos com o intuito de mostrar que quando se trata de Gestão de Projetos no campo do Design, como ocorre no caso da Designeria, Empresa Júnior foco da investigação, percebeu-se que cada vez mais essa gestão envolve trabalho colaborativo. Por isso, é de suma importância conhecer as dinâmicas existentes entre processos e pessoas, além de atentar-se para a forma como se empregam os recursos - mantendo a responsabilidade, a fim de agregar valor não só ao resultado final, mas à credibilidade com os clientes e usuários. No estudo teórico que resultou na pesquisa ora exposta, foi realizada uma relação en- 
tre o designer como gestor - na perspectiva da pesquisadora Mozota (2001) - que considera que uma gestão focada no Design envolve mais do que a realização das tarefas técnicas atribuídas a um designer. Segundo ela, também inclui tarefas administrativas, rotineiras que fazem parte das responsabilidades de um gerente de Design, tais como a gestão de pessoas; a gestão financeira de procedimentos administrativos e também a gestão de projetos. Outrossim, para que as atividades de uma organização possam ser desenvolvidas com união e coerência a empresa deve possuir uma cultura organizacional bem estabelecida. Com isso, percebe-se que hoje existe a utilização do campo do Design para que essas metas sejam atingidas. E foi a partir desses estudos que foi possível conceber que na Designeria Empresa Júnior, uma empresa composta por estudantes de Design, era difícil dissociar todos os processos de gestão do campo do Design, por este motivo identificou-se o potencial para o desenvolvimento de uma plataforma que auxiliasse o gerenciamento dos projetos na empresa. A seguir serão apresentadas informações sobre a empresa, bem como o processo de projetação e o produto resultante da investigação: o Gestor Júnior.

\section{DESIGNERIA EMPRESA JÚNIOR}

A Designeria Empresa Júnior foi fundada em 5 de novembro de 2010, data em que no Brasil se comemora o dia do Designer. Foi uma iniciativa dos alunos do curso de Design Gráfico da Universidade Federal de Pelotas, após o primeiro contato que tiveram com o conceito de Empresa Júnior - que Ihes foi apresentado no evento NDesign ${ }^{[5]}$ no ano de 2010. Esta foi criada com o propósito de proporcionar experiências profissionais que complementassem o aprendizado obtido dentro da instituição a fim de capacitar seus membros, alunos do curso de Design, para o mercado de trabalho. A Designeria nasceu, então, como um projeto de extensão vinculado aos cursos de Design, possuindo, portanto, vínculo com a Universidade Federal de Pelotas.
[5] Encontro Nacional dos Estudantes de Design é um evento sem fins lucrativos que ocorre anualmente, planejado por estudantes para estudantes, com cunho acadêmico. Disponível em: https://www.designbrasil.org. br/design-em-acao/n-design/ Acesso em 05 Out. 2020. 
A missão da empresa, inicialmente, era oferecer serviços de qualidade em Design a um preço mais baixo em relação aos praticados pelo mercado - para empreendimentos que buscassem soluções em Design. Naquele momento o público alvo eram pessoas físicas maiores de idade e jurídicas internas e externas à UFPel (Plano de Negócio Designeria Empresa Júnior). Suriz e Silva (2016, p.21) expõem as particularidades desse público:

\section{Com relação ao público externo, esse se configura por micro e pequenas empresas (MEIS), normalmente constituídas por pessoas que estão começando a constituir os seus empreendimentos - ou que já tenham uma empresa em atuação e precisam de trabalhos para qualificar ainda mais esse desempenho. Esse perfil de clientes tem a intenção de ampliar os negócios e, por isso, sabe que o design é um importante campo do conhecimento capaz de acelerar esse processo.}

Na Designeria os projetos nascem, normalmente, porque um cliente interno ou externo à UFPel identificou uma necessidade de um usuário ou grupo que ainda não foi atendido. Desta forma, surgem demandas de consumo e até mesmo oportunidades para empreender. Através dos canais de contato da empresa, o cliente pode contatar a Designeria para a solicitação de serviços. Após o primeiro contato, o secretário responsável pelos pontos de contato com o cliente encaminha a solicitação para a equipe da Designeria (Silva, 2019). A partir desse momento dois integrantes se disponibilizam a receber o cliente para a sistematização do briefing. Em geral, um dos participantes que está há mais tempo na empresa é acompanhado por um novo integrante - para que esse aprenda como se dá o primeiro contato presencial com o cliente. Esse atendimento sempre se dá em dupla - evitando que um discente fique sozinho com um cliente que a empresa ainda não conheça; para que um auxilie o outro na compreensão das necessidades do cliente e para a memorização dessas solicitações. Com a reunião agendada, os membros escalados recebem o cliente para uma conversa inicial, sempre que possível 
nas dependências da Designeria. Nessa oportunidade o solicitante do serviço expõe as particularidades que deseja para seu projeto e os acadêmicos ali presentes orientam e tiram dúvidas do mesmo. Após a reunião com o cliente lhe é enviado um e-mail contendo um link do formulário Google que serve como briefing durante o projeto. Em seguida, esses dados, são expostos nas reuniões com toda a equipe da Designeria que ocorrem semanalmente. Durante essas reuniões é que as novas demandas são apresentadas aos membros, que discutirão sobre a viabilidade de execução das mesmas, bem como a definição de quais alunos irão integrar o grupo de desenvolvimento de cada trabalho. Dessa forma, posteriormente a definição dos grupos, um orçamento é discutido e elaborado durante o encontro e, assim que definido, é encaminhado via e-mail para o cliente. O serviço é formalizado por meio de um contrato que determina os tipos de trabalhos a serem desenvolvidos, prazos, número de alterações estipuladas e formas de pagamento (CALDEIRA; MARQUES, 2018).

Com o contrato assinado, a equipe responsável pelo projeto começa a confecção do trabalho, mantendo contato com o cliente e seguindo os prazos definidos. É importante ressaltar que para a comunicação interna dos membros durante a execução dos projetos são utilizados atualmente grupos no WhatsApp e no Facebook, já que a estrutura da Designeria não permite que todos os colaboradores permaneçam trabalhando em um mesmo ambiente de trabalho. Cada etapa do processo é apresentada para que o cliente se sinta parte do processo e possa fazer parte das tomadas de decisão, além de serem minimizadas as refações. O encerramento do projeto só ocorre após todas as alterações solicitadas serem atendidas e mediante a aprovação do cliente. Todos os arquivos das peças produzidas e suas devidas aplicações são encaminhados para o cliente via e-mail, dessa forma fechando o ciclo do projeto por parte da Designeria Empresa Júnior.

Em linhas gerais essas são as etapas de organização da equipe. Foi necessário apurar dados sobre a formação da Em- 
presa Júnior de Design para que fosse possível compreender sua organização e, em especial, para entender como ocorre a gestão dos projetos internamente. Tudo isso para que fosse possível construir uma ferramenta adequada às necessidades da mesma. A partir dos dados coletados e expostos até aqui, parte-se, no próximo tópico, para a apresentação do desenvolvimento da plataforma Gestor Júnior.

\section{PRÁTICA PROJETUAL: GESTOR JÚNIOR}

Para a realização da prática projetual foi estabelecido um fluxo que guiasse o usuário da home até a página final do cadastro de um projeto. Para isso, como já mencionado, utilizou-se a metodologia de Garrett (2011) que é dividida em 5 etapas que colaboram para o desenvolvimento de interfaces digitais, sendo elas: Estratégia, Escopo, Estrutura, Esqueleto e Superfície. Tal metodologia contribuiu para a orientação da experiência do usuário, pois parte de uma forma abstrata para uma mais tangível. Para isso, a primeira etapa, e mais abstrata, é a do plano de Estratégia. Nela define-se o que se quer comunicar e para quem, momento no qual são realizadas pesquisas e análises para as posteriores definições dos objetivos a serem traçados. Na sequência é estabelecido o plano de Escopo, no qual se estabelece as características desse produto, ou seja, determina-se quais serão os conteúdos dessa interface, decidindo o que será ou não necessário para, dessa forma, partir para o plano de Estrutura. Este, foca em hierarquizar as informações da plataforma.

Por fim, alcança-se as etapas mais complexas e mais visuais as quais correspondem aos planos de Esqueleto e de Superfície - que contemplam o desenvolvimento da estrutura de um site. No Esqueleto, então, define-se a navegação dentro da plataforma apontando como as informações do site serão apresentadas visualmente. Com essas definições, é necessário delinear como será a estrutura da interface, através da elaboração de esboços dessa estrutura representada de forma gráfica. Esses, por sua vez, são denominados de wireframes e servem como base para a última etapa, o plano 
de Superfície. Neste último nível se concentra o desenvolvimento das visualidades presentes no site que, conjuntamente com as outras etapas formadas, é capaz de proporcionar, além de uma interface eficiente, um produto intuitivo.

$\mathrm{Na}$ etapa da estratégia, por sua vez, é fundamental delimitar os objetivos de um projeto e entender as demandas dos usuários. Sendo assim, realizou-se um benchmarking, expondo uma análise de plataformas, Trello e Operand, que têm o mesmo propósito do Gestor Júnior, em busca de funcionalidades existentes nelas e que ajudassem a enriquecer o resultado prático da investigação (SILVA, 2019). Para além da análise competitiva, utilizou-se também os resultados obtidos através de um questionário contendo questões abertas. Este foi aplicado em 6 ex-integrantes da Designeria Empresa Júnior que exerceram junto à empresa alguma função de gerenciamento. Através da síntese desses resultados foi possível definir uma lista objetiva com as reais necessidades encontradas, tais como: "Agenda", para que exista um controle de prazos dos projetos; "Armazenamento de arquivos", para que os integrantes possam compartilhar documentos; "Painel de controle", para uma visão sistêmica dos projetos em andamento; “Líder da equipe”, uma funcionalidade para o administrador apontar um responsável por um projeto. O líder será o responsável por manter o sistema atualizado dando vistas ao gestor geral; "Chat" ou espaço para comentários, que terá como objetivo manter o diálogo entre o grupo; "Inserção de membros", que servirá para escalar as pessoas que farão parte do projeto; "Status", para informar aos usuários do aplicativo o estágio das tarefas.

Ao analisar de forma geral o retorno dado ao questionário contento questões abertas observou-se (ver Figura 1) que esta etapa foi de suma importância, pois trouxe para pesquisa muitas informações e sugestões para serem utilizadas na plataforma projetada. As funcionalidades sugeridas pelos participantes foram organizadas no quadro apresentado a seguir, contemplando aquelas consideradas relevantes, em especial se comparadas com a análise feita no benchmarking. 
Funcionalidades

Administrador

Agenda

Armazenamento de arquivos

Líder de Equipe

Chat ou Comentário

Inserção de membros

Status

Gerenciamento de Cliente

Gerenciamento de membros da empresa

Painel de controle

Check-list de subtarefas

Emissão de relatório

Timesheet (Cronômetro)

Criação e personalização de perfil

Projetos Inativos e Membros Inativos

Registros de atividades

Figura 1: Quadro de funcionalidades coletadas após analise estratégica. Fonte: Dados da pesquisa.

Ainda no plano da estratégia, após estudar sobre a Designeria Empresa Júnior foi possível delimitar os potenciais usuários que iriam fazer uso da Gestor Júnior. Em linhas gerais os colaboradores que participam da empresa são estudantes matriculados nos cursos de Design Digital e Design Gráfico 
da UFPel, também são usuários os docentes coordenadores e colaboradores do projeto de extensão da Designeria. Por isso, foram criadas as personas (ver Figura 2), que são personagens fictícios desenvolvidos para representar de forma mais real possível quem é o usuário que fará uso do aplicativo projetado, pois se colocar um rosto e um nome nessa persona fica mais fácil manter o usuário em mente durante o processo de Design. Com isso, é possível seguir de forma mais fiel as necessidades do usuário (GARRETT, 2011). A seguir, a título de exemplo, apresenta-se uma persona criada:

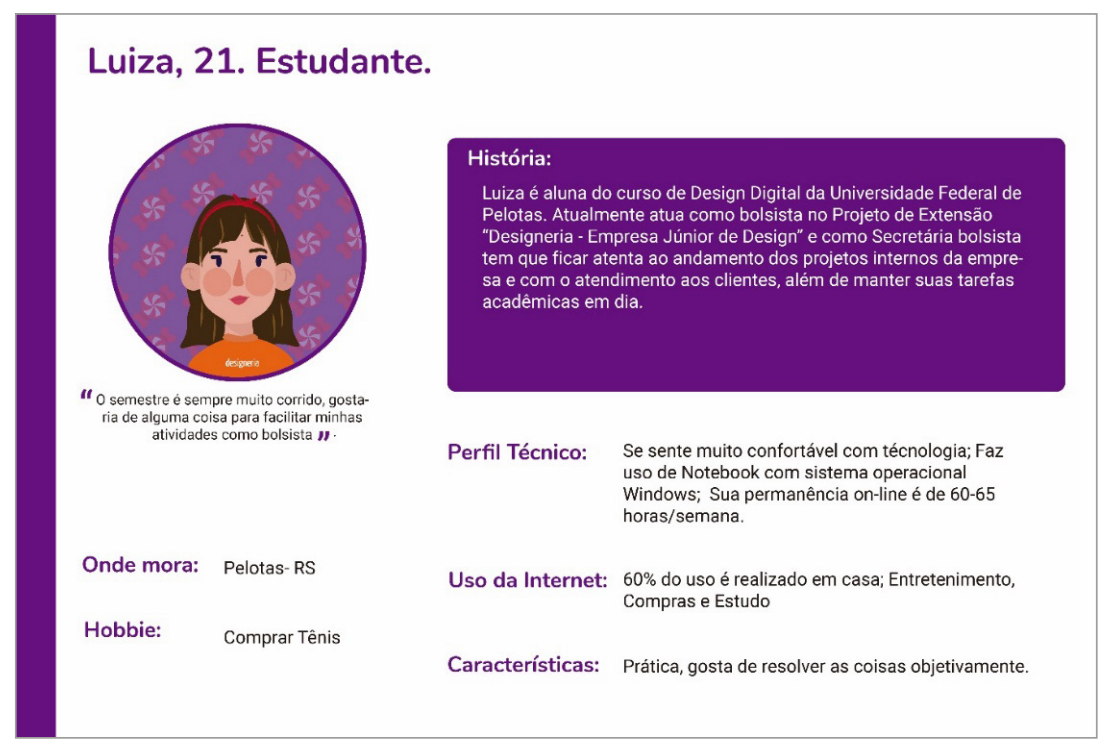

Figura 2: Persona 2 (Luiza). Fonte: Acervo Pessoal.

A partir das definições das personas, foi possível realizar o aprofundamento e a lapidação dos resultados obtidos na primeira etapa, passando então para o plano de escopo. Para Garrett (2011), o Escopo é uma parte valiosa do projeto, pois força aquele que está projetando a lidar com os possíveis conflitos e pontos difíceis do produto, tudo isso em um momento que esse produto é hipotético, logo auxiliando a prevenir erros ou falhas ao longo do projeto. Nesta etapa foram apresentadas as Especificações do Sistema, Especificações Funcionais da plataforma e a Jornada do Usuário, como exposto a seguir (ver Figura 3). 


\section{Jornada do Usuário}

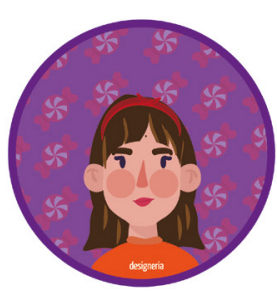

Luiza, 21. Estudante

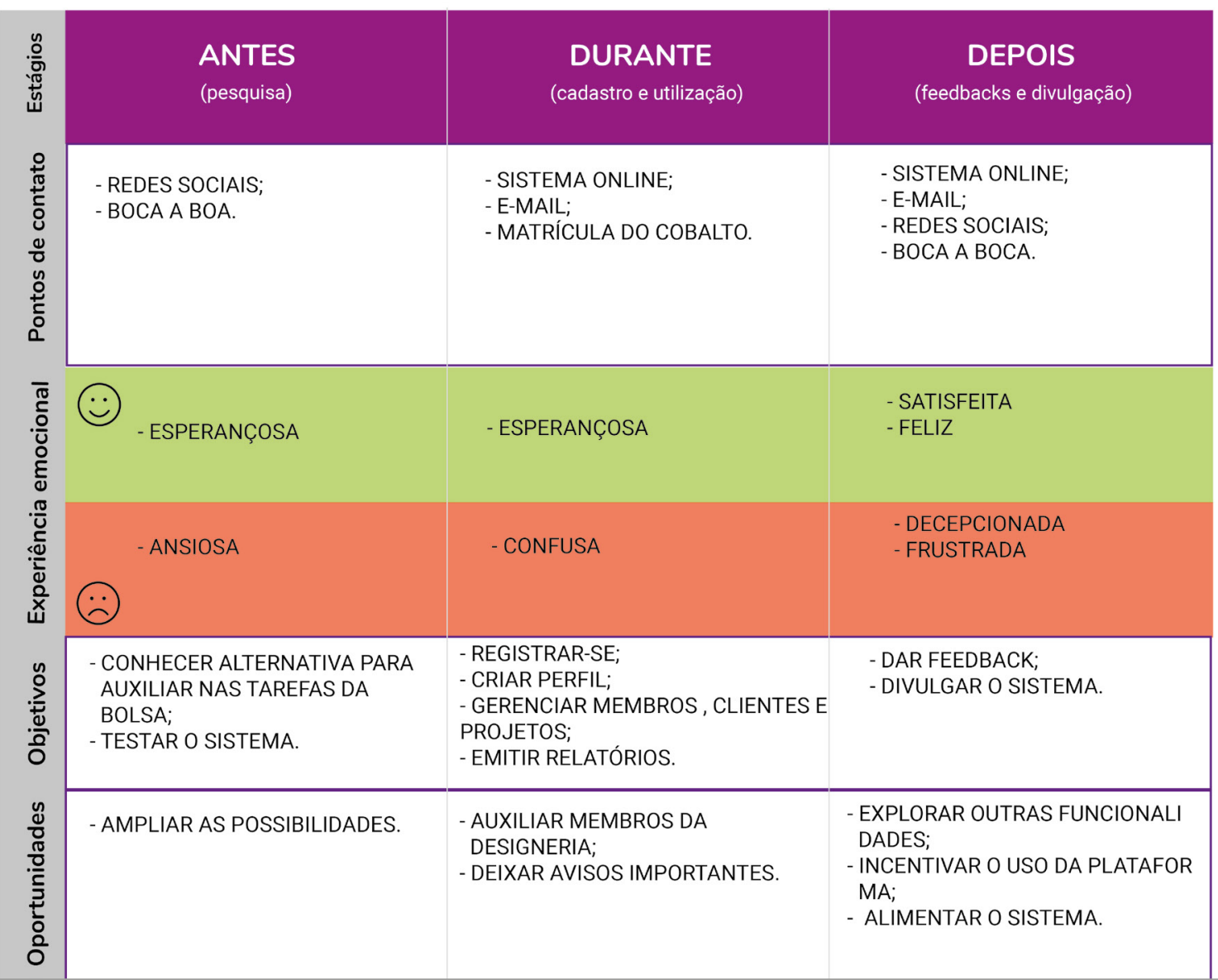

Figura 3: Jornada do usuário - Luiza. Fonte: Acervo pessoal.

No Plano da Estrutura, que para Garrett (2011) é onde o abstrato e o concreto começam a se misturar, apresentou-se a definição do Design de Interação, que prevê como o sistema se comportará em resposta ao usuário incluindo a Arquitetura de Informação - responsável por apresentar a organização do conteúdo dentro do sistema. Para a definição do Design de Interação foram realizados fluxogramas das três personas definidas no Plano da Estratégia. Já para a Arquitetura da Informação foi realizado um cardsorting ${ }^{[6]}$ e, posteriormente, um mapa do site que foi estruturado após a análise dos dados da ferramenta cardsorting. A seguir é possível visualizar um dos três fluxos construídos (ver Figura 4), com base nas necessidades da Luiza, uma das três personas construídas ${ }^{[7]}$.
[6] Card Sorting é uma

ferramenta muito utilizada na etapa de arquitetura de informação; serve para entender o modelo mental de como as pessoas agrupam conteúdo e funcionalidades. Disponível em: encurtador.com.br/bcsM1 acesso em 30 de Set. 2019.

[7] Para saber mais sobre as demais personas desenvolvidas ler (SILVA, 2019). 
O fluxo da Luiza, definida como secretária na investigação (SILVA, 2019), representa o perfil dos alunos que já possuem mais experiência na empresa, logo lidam com a gestão de forma mais cotidiana. Esse fluxo é bem característico, e apesar de não parecer complexo, o preenchimento dos dados da criação de um projeto é uma etapa importante que será executada dentro da plataforma. Contudo, antes disso acontecer, ocorre todo um processo externo de coleta de dados que precisará ser alimentado por essa persona neste sistema. Desta forma, trata-se de um perfil que deverá ter um maior controle do que ocorre na empresa. Na sequência, para uma maior compreensão, apresenta-se o fluxograma da persona Luiza.

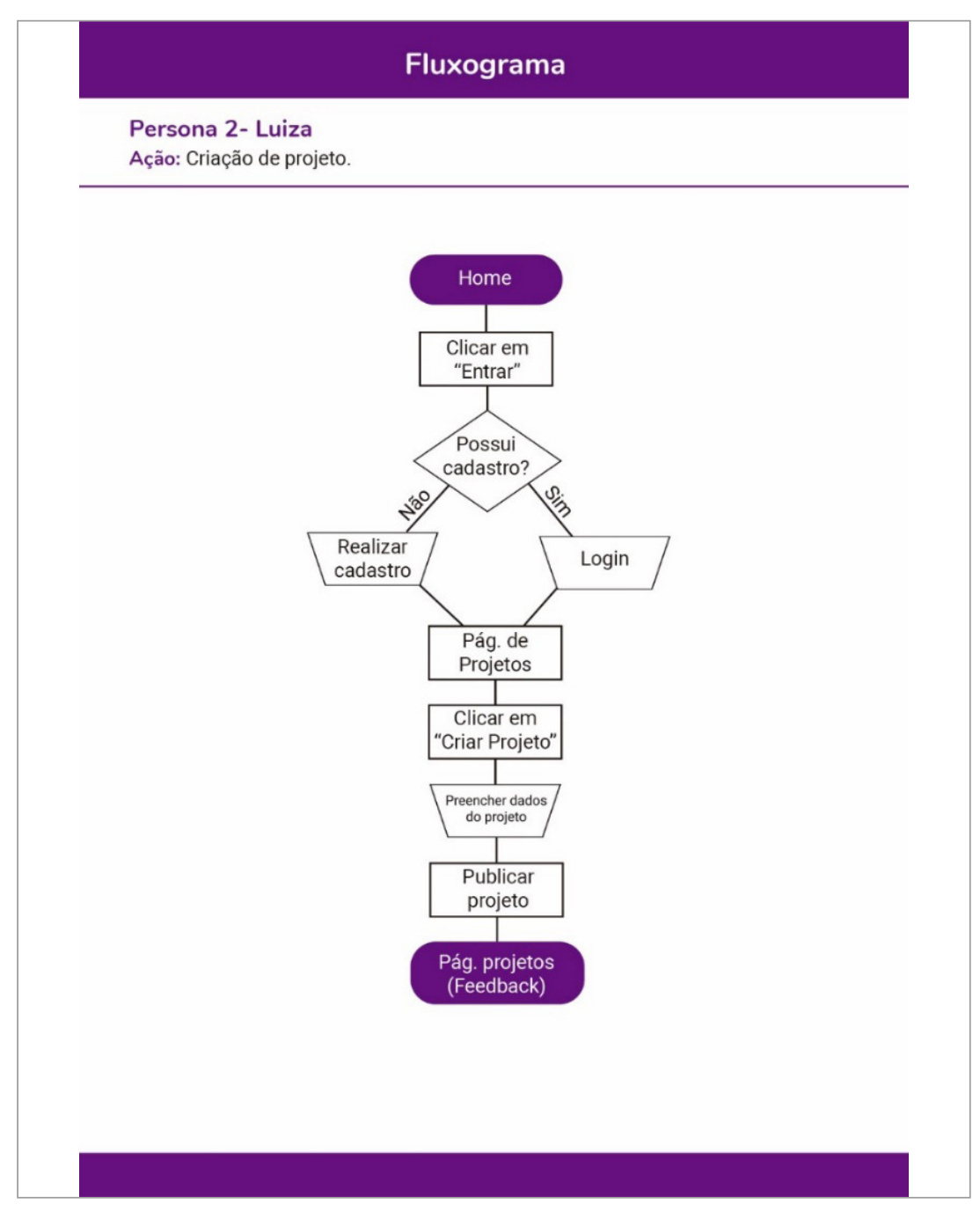

Figura 4: Fluxograma- Luiza. Fonte: Acervo Pessoal. 
Ainda no plano da estrutura foi aplicada a técnica cardsortign em pessoas que possuíam o perfil do público alvo definido. Para realizar o cardsorting desta investigação, foi utilizada a plataforma online denominada de Optimal Workshop ${ }^{[8]}$, a qual tem foco em pesquisas com usuários. Utilizou-se a funcionalidade OptimalSort (ver Figura 5) que permite a cria-

[8] Disponível em: https:// www.optimalworkshop. com/optimalsort acesso em 17 de Nov. 2019. ção de um cardsorting online compartilhável através de um link. Para o teste optou-se por expor categorias pré-definidas, as quais foram selecionadas após a análise das estruturas das plataformas do benchmarking. Também foram criados os itens de acordo com as principais funcionalidades definidas pela investigação (ver Figura 6). Após essa organização foi encaminhado o link da pesquisa para quatro membros da Designeria, os quais tiveram que organizar os itens dentro das categorias pré-definidas - de forma muito semelhante, com poucas diferenças entre si, gerando um resultado importante para que fosse possível pensar o sistema, como pode ser observado a seguir.

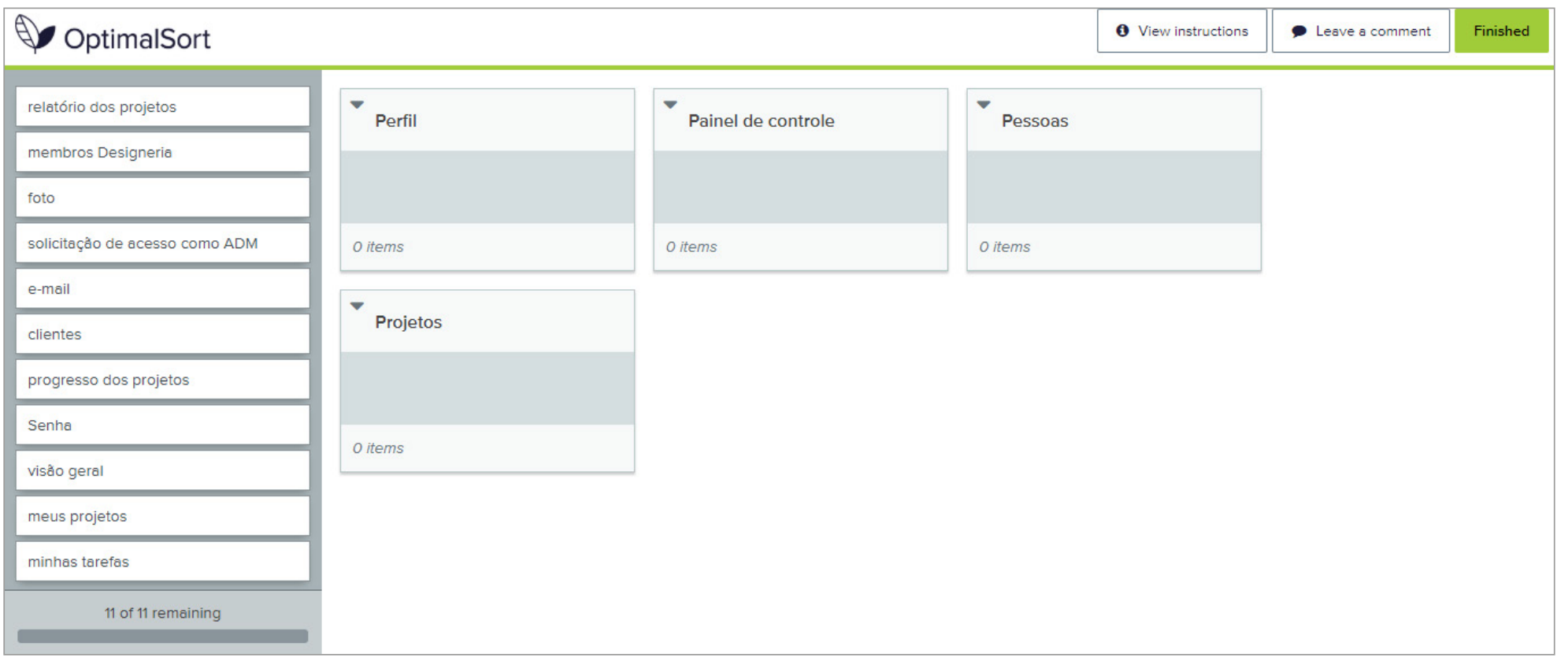

Figura 5: Cardsorting online. Fonte: Dados da pesquisa. 


\section{Popular placements matrix}

\begin{tabular}{|c|c|c|c|c|}
\hline & Projetos & Painel de controle & Pessoas & Perfil \\
\hline meus projetos & $100 \%$ & & & \\
\hline minhas tarefas & $100 \%$ & & & \\
\hline visåo geral & $100 \%$ & & & \\
\hline progresso dos projetos & & $100 \%$ & & \\
\hline relat6rio dos projetos & $25 \%$ & $75 \%$ & & \\
\hline solicitaçăo de acesso como ADM & & $50 \%$ & & $50 \%$ \\
\hline clientes & & & $100 \%$ & \\
\hline membros Designeria & & & $100 \%$ & \\
\hline Senha & & & & $100 \%$ \\
\hline foto & & & & $100 \%$ \\
\hline e-mail & & & $25 \%$ & $75 \%$ \\
\hline
\end{tabular}

Com base nos resultados obtidos com o cardsorting foi possível desenvolver o mapa do site, que possibilitou a construção dos wireframes de baixa fidelidade do Plano do Esqueleto. Este é dividido em três partes: Design de interfaces, o qual consiste no domínio dos componentes da interface, que proporciona a capacidade de realizar tarefas aos usuários; Design de navegação, que abrange o modo como os usuários deslocam-se pelas informações nas várias áreas do site; Design da informação, que é voltado para a comunicação com o usuário (GARRETT, 2011). Nesta etapa da investigação foram apresentados os wireframes de baixa fidelidade que serviram de base para a construção das telas. Os esboços foram realizados à mão utilizando apenas papel e grafite para sua confecção (ver Figuras 7 e 8).

Após o desenvolvimento do esboço das Wireframes, contendo a definição das funcionalidades, partiu-se para o Plano de Superfície. No Plano da Superfície chega-se na última etapa da metodologia de Garrett (2011), na qual o projeto atinge o seu estado mais concreto. Esse plano salienta o Design Visual contendo os aspectos do site que o usuário perceberá de forma instantânea. É nessa etapa que as funcionalidades, o conte- 


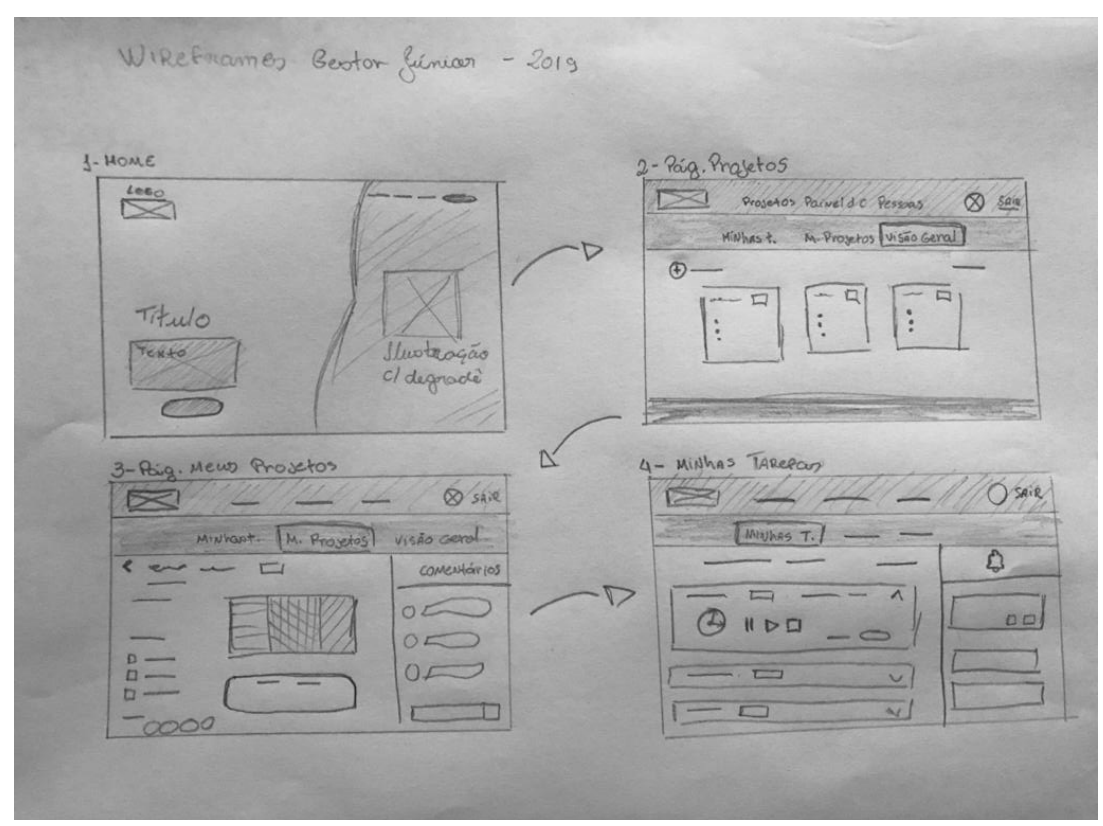

Figura 7: Wireframes parte 1

Fonte: Acervo pessoal.

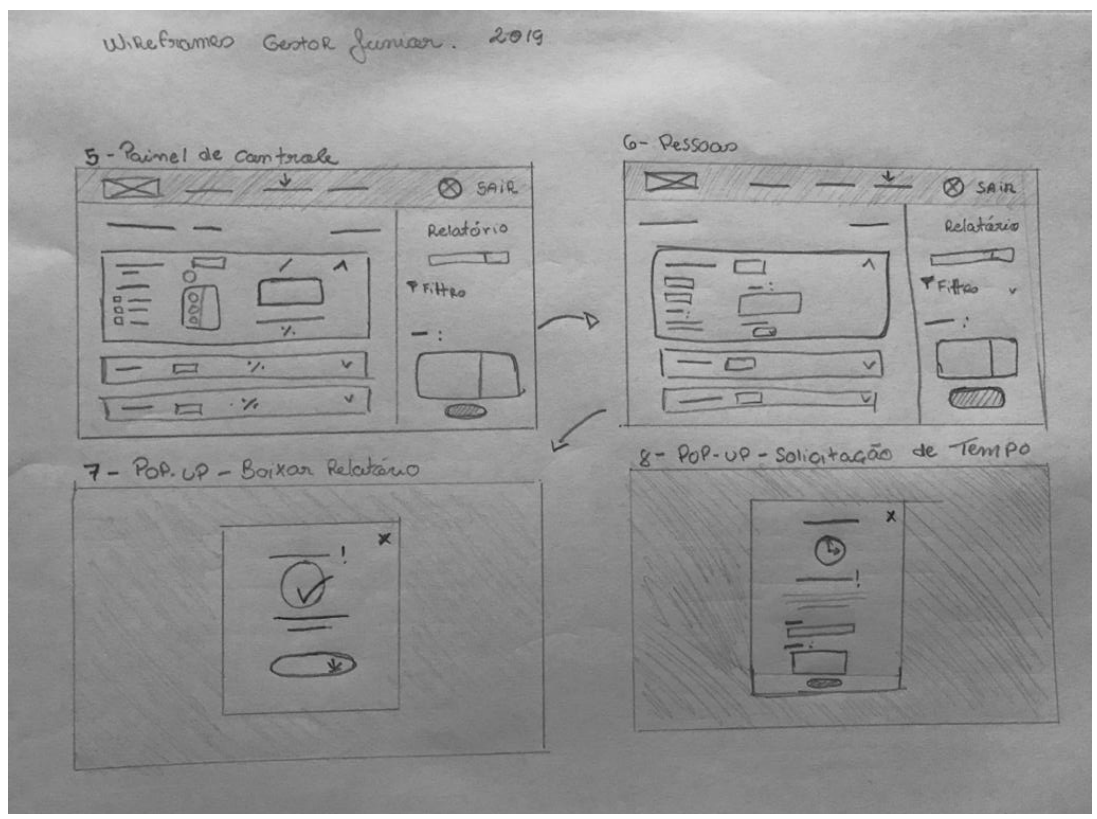

Figura 8: Wireframes parte 2 Fonte: Acervo pessoal.

údo e a estética se unem para produzir um Design bem elaborado que suporte os outros planos presentes na metodologia (GARRETT, 2011). Nessa etapa foi necessária a definição de um nome para a plataforma e, consequentemente, a criação de uma Identidade Visual. O processo de naming, como é chama- 
do o modo de escolha do nome, se deu em função do perfil das pessoas que buscariam utilizar essa plataforma, além de levar em consideração o nicho específico que a plataforma busca atingir, qual seja: o das empresas juniores (GURGEL, 2009). Com isso definiu-se que o nome da plataforma seria Gestor Júnior que remete literalmente a jovens gestores, buscando ser uma plataforma voltada para empresários juniores (ver Figura 9).

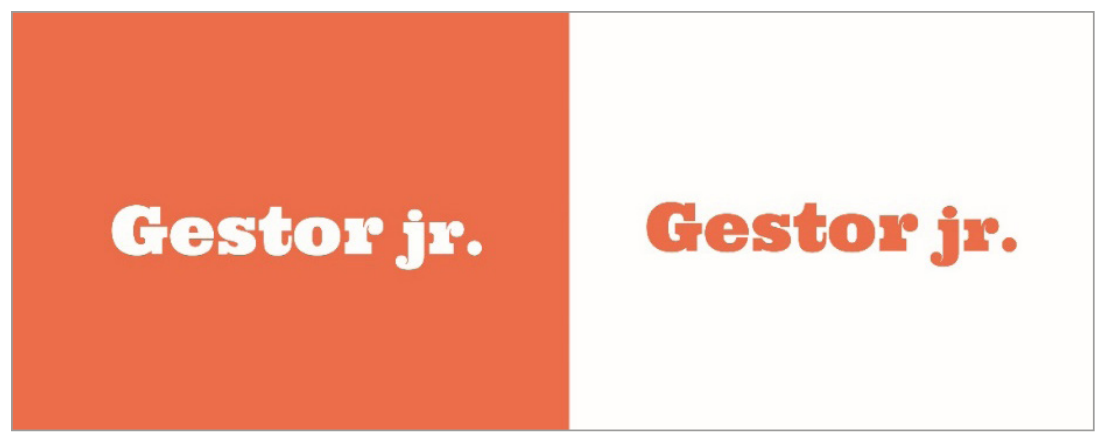

Nesta etapa também foi necessário expor as telas produzidas para a plataforma Gestor Júnior (ver Figura 10), explicando o conteúdo visual que exerceu a função de um memorial descritivo do sistema. As telas foram desenvolvidas visando atender as principais necessidades da empresa constatadas ao longo da investigação e foram produzidas através do aplicativo Adobe $X D$, que é voltado para a produção visual de aplicativos da Web e de aplicativos móveis. Tais telas poderão ser verificadas a seguir:

Após a confecção das telas, foi realizado um protótipo navegável para a conclusão da prática resultante da investigação. Este foi desenvolvido para poder divulgar as principais funcionalidades do sistema. Para isso, foram escolhidos dois fluxos para o protótipo, foram eles o da persona Luiza, responsável por criar um projeto novo dentro do sistema, e o da Helenita - que, como professora coordenadora, teria como objetivo gerar um relatório dos membros da empresa. $\mathrm{O}$ intuito com o protótipo navegável foi o de apresentar um pouco do que foi planejado para o Gestor Júnior.
Figura 9: Marca prioritária Gestor Júnior. Fonte: Acervo Pessoal. 


\section{Telas - Gestor Júnior}
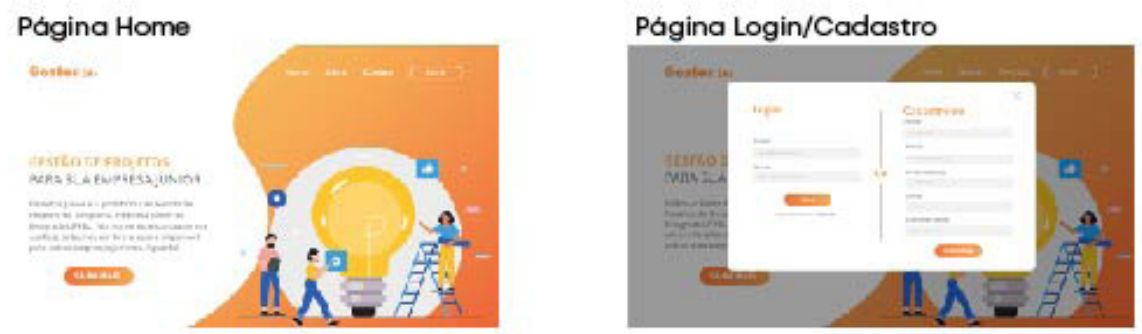

\section{Página Projetos -Visăo geral}
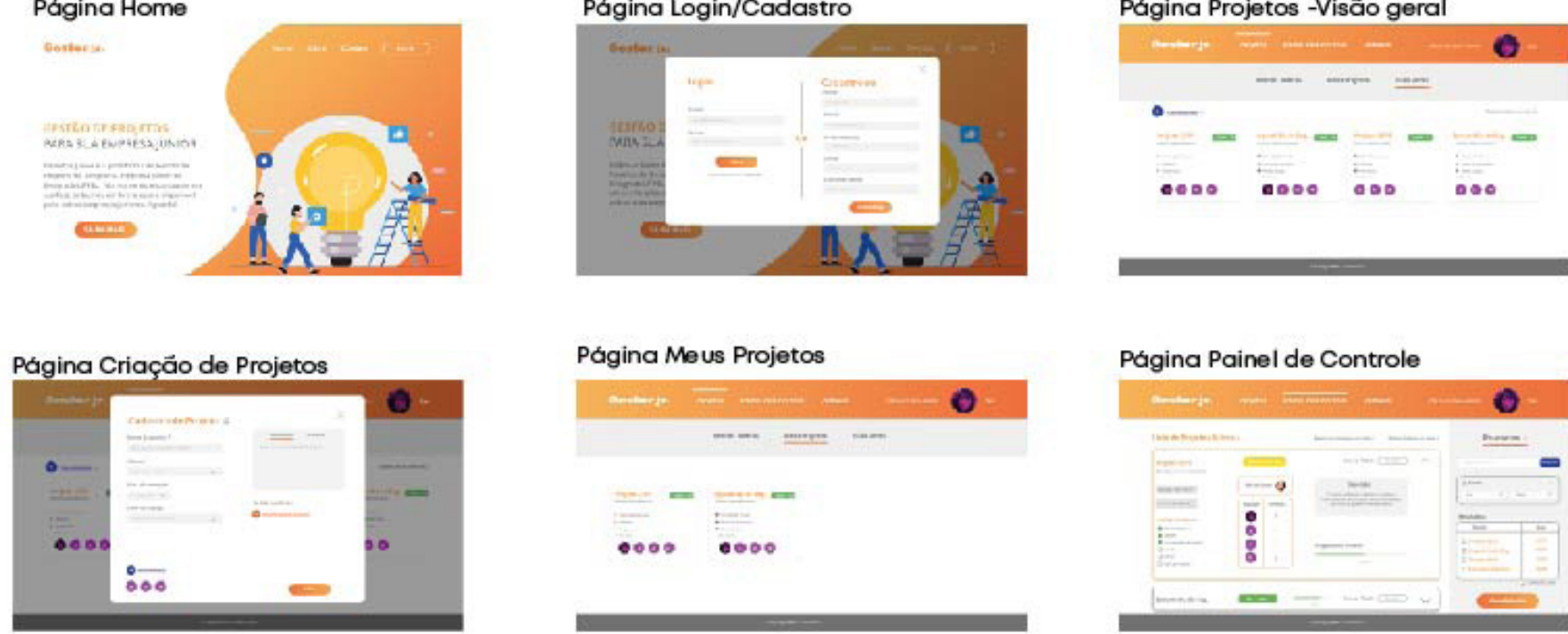

Página Meus Projetos

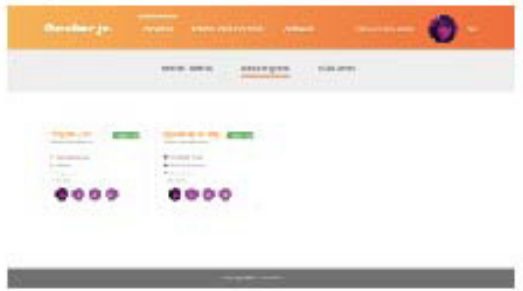

\section{Página Painel de Controle}

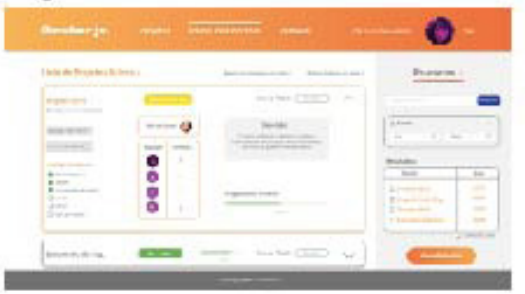

Figura 10: Telas Gestor Júnior. Fonte: Acervo pessoal

Gestore jir. Projetos Painel de Controle Pessoas Olá, Luizal Bem-Vinda!

Minhas Tarefas Meus Projetos Visão Geral

\section{< Projeto CEPE Ativo}

Cliente: Álvaro Moreira

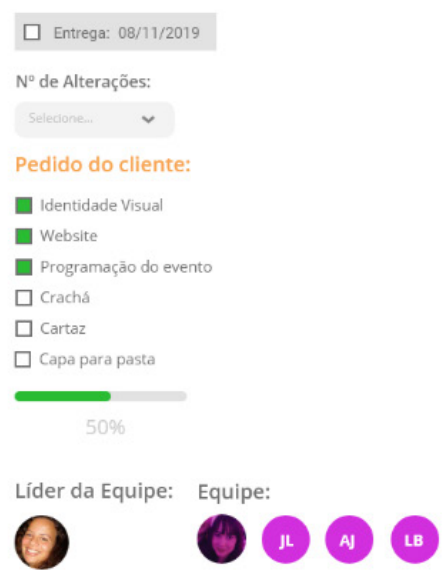

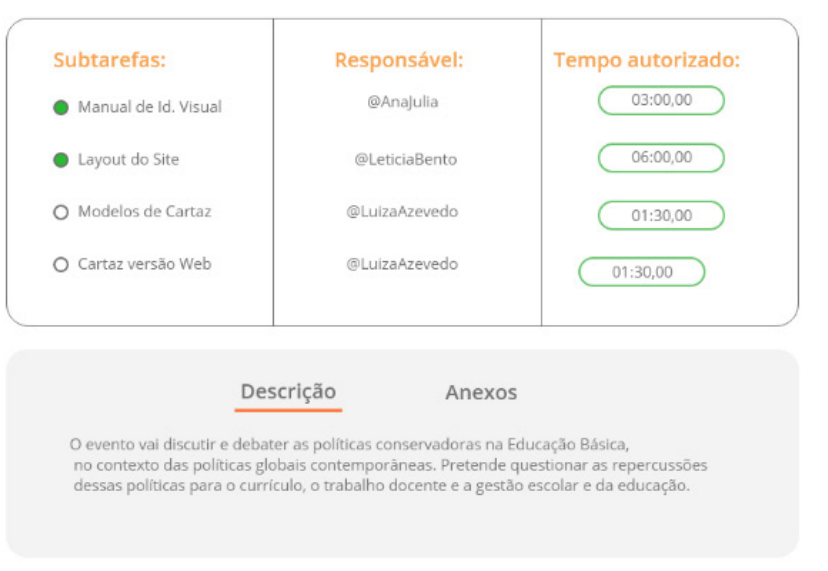

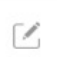

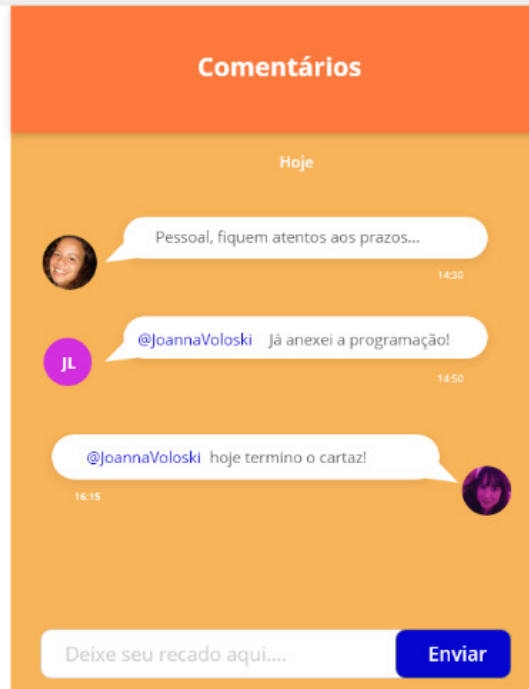

\section{O Copyright 2019 - Gestor Júnior}

Figura 11: Página expandida de um projeto. Fonte: Acervo pessoal. 


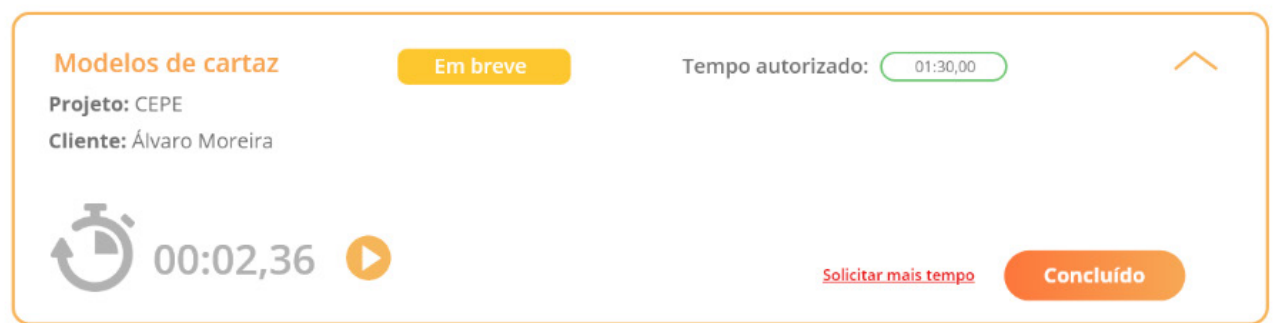

\section{Cartaz versão Web}

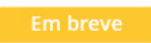

Tempo autorizado:

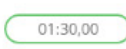

No Prazo

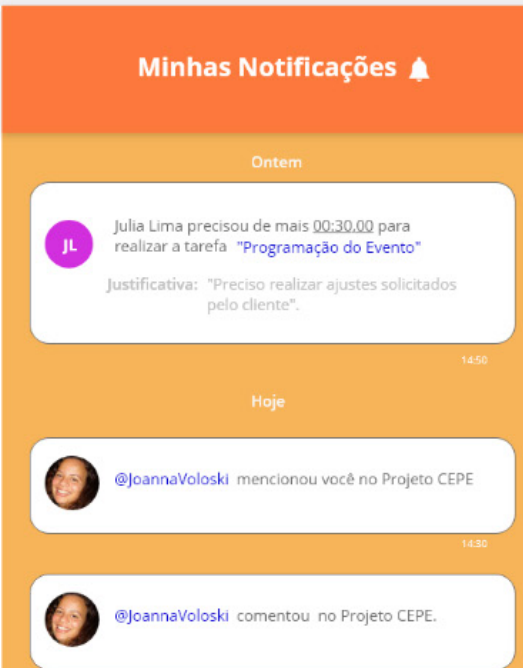

OCopyright 2019 - Gestor Júnior

Figura 12: Página Minhas Tarefas. Fonte: Acervo pessoal.

Cabe destacar que o protótipo navegável foi enviado para teste - que consistia em navegar os fluxos pré-determinados - desempenhados pelos quatro membros da Designeria que já tinham realizado o teste do cardsorting - a fim de garantir que as funcionalidades estavam alinhadas com os resultados obtidos (ver Figura. 13).

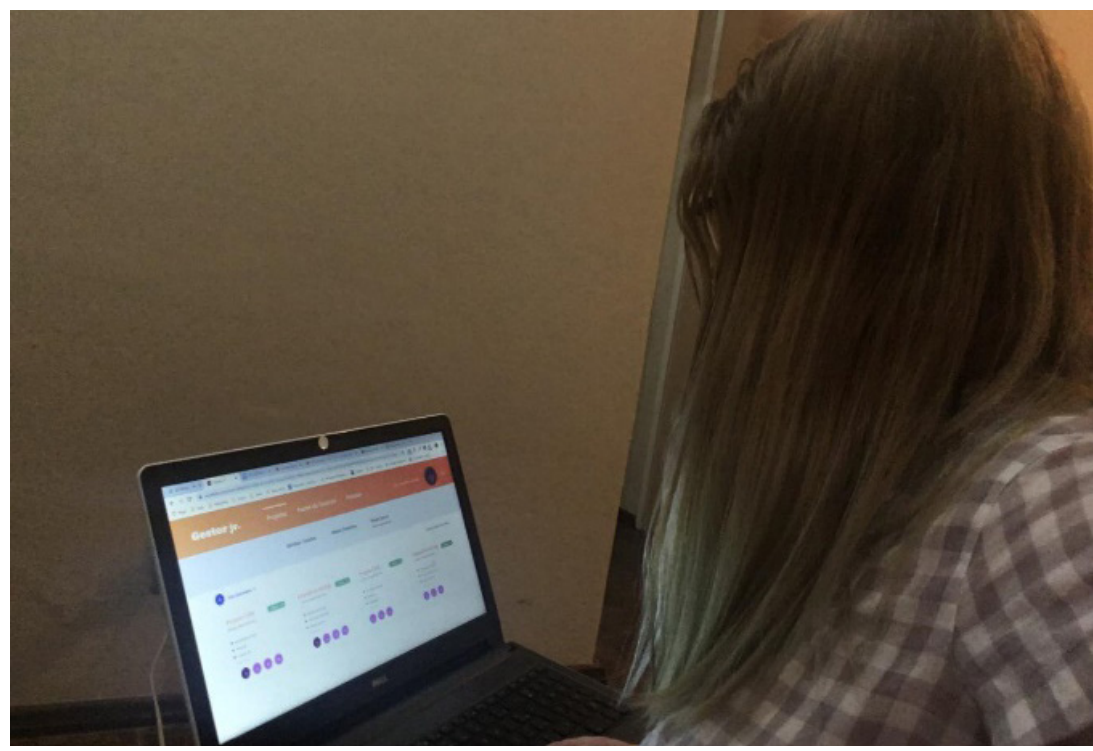

Figura 13: Feedback - Membro da Designeria testando Protótipo. Fonte: Acervo pessoal. 
Em consequência das limitações da ferramenta, os protótipos interativos permitem apenas uma experiência mais introdutória sobre as funcionalidades, não consentindo a exibição de todas as interações do sistema, mas possibilitando uma breve compreensão do funcionamento da plataforma. Ainda assim, nesta etapa os participantes do teste não identificaram problemas no sistema proposto.

Outro aspecto a ser destacado é que, por mais que a plataforma tenha sido elaborada para a Designeria Empresa Júnior, ela tem potencial para ser escalável. Isso significa que tal produto digital tem potencial de ser utilizado por organizações com um modelo de negócio similar, sem necessitar de altos investimentos - uma vez que a mecânica do seu funcionamento já foi projetada.

Ao concluir a investigação, contudo, indicou-se que novos encaminhamentos poderão ocorrer - em especial tornar a plataforma Gestor Júnior um aplicativo móvel. Este, por sua vez, deverá ter funcionalidades reduzidas, facilitando a interação do usuário que poderá ter acesso à plataforma com a mobilidade que os aplicativos proporcionam.

\section{CONSIDERAÇÕES FINAIS}

A investigação aqui debatida originou-se em função de uma motivação pessoal da autora, que desde o começo de sua graduação se identificou com áreas e funções voltadas à gestão - por mais que ainda não soubesse da existência da área de Gestão do Design. No decorrer de sua jornada acadêmica, se deparou com as possibilidades do uso da gestão, mas foi apenas quando se tornou membro da Designeria Empresa Júnior que pode, de fato, identificar e vivenciar na prática a aplicação da Gestão associada ao Design.

Com a realização da investigação cujo recorte foi exposto neste artigo, notou-se que campo da Gestão e do Design caminham lado a lado e, por vezes, se cruzam. Isso porque, cada vez mais, o profissional designer vem se destacando no mercado, não apenas pelo senso estético, mas também pelo 
pensar estratégico. As reflexões realizadas com a investigação mostram que para uma empresa é indispensável uma cultura organizacional bem estabelecida e que o Design vem cada vez mais sendo utilizado para que essa meta seja atingida. Por meio dessas análises ficou evidente como a experiência proporcionada pela Designeria - com clientes reais de mercado - pode possibilitar o exercício da prática da gestão no dia a dia do graduando.

Destaca-se, ainda, que foi de suma importância para a referida investigação os métodos de coleta de dados. A entrevista não-estruturada com ex-integrante da empresa; o questionário contendo questões abertas aplicado com os ex-membros que exerceram cargos de gestão e a análise documental - a partir do uso de diversos documentos internos da empresa que auxiliaram a compreender um pouco mais sobre a história da Designeria e bem como de seus processos. Isso permitiu refletir sobre a estrutura organizacional da mesma, além da realização de uma comparação de como a empresa se encontra atualmente. Nesse quesito, foi relevante observar sua estrutura organizacional, os serviços prestados e, principalmente, seu processo de gerenciamento de projetos. Os estudos de caso fizeram com que ocorresse o entendimento dos trâmites envolvidos na gestão de projetos da Designeria - sem esses seria complexo refletir sobre determinadas funcionalidades adicionadas à plataforma. Torna-se necessário destacar, no que se refere à coleta de dados, o interesse dos ex-integrantes em participar da pesquisa e a qualidade das informações socializadas - esse fato expõe o quanto essa Empresa Júnior toca as pessoas que dela participam ou participaram.

Já com relação à definição da metodologia de Garrett (2011) para o desenvolvimento do estudo, percebe-se que essa foi fundamental para que houvesse uma organização e estruturação efetiva. Isso auxiliou na construção de uma plataforma consistente e coerente com as necessidades da empresa, que tem potencialidade para ser escalável para a 
realidade de outras empresas, além de proporcionar uma fácil curva de aprendizado para que fosse atrativa e acessível para os membros da Designeria.

Por meio dos esforços empreendidos para a execução da prática resultante da investigação, acredita-se que o objetivo maior da pesquisa e deste artigo foram atingidos. Ao concluir a investigação, contudo, indicou-se que novos encaminhamentos poderão ocorrer - em especial tornar a plataforma Gestor Júnior um aplicativo móvel. Este, por sua vez, deverá ter funcionalidades reduzidas, facilitando a interação do usuário que poderá ter acesso à plataforma com a mobilidade que os aplicativos proporcionam.

Por fim, diante de todo o exposto, conclui-se a exposição desses resultados esperando que o recorte aqui apresentado possa despertar o interesse dos estudantes de Design pela área da Gestão - ilustrando a eles que essas duas áreas podem andar de mãos dadas. Além disso, que eles compreendam, com esta investigação, que o trabalho de um designer nunca se trata somente de projetos, mas de pessoas.

\section{REFERÊNCIAS BIBLIOGRÁFICAS}

\section{BEST, Kathryn. Fundamentos de Gestão do}

Design. Porto Alegre: Bookman, 2012.

CALDEIRA, Camila Soares; MARQUES, Natália Marroni; NEVES, Helena de Araujo; Criação de identidades

visuais para eventos: projetos designeria empresa júnior. In: CONGRESSO DE EXTENSÃO E CULTURA DA UFPEL, Pelotas, 2018. Anais...Pelotas: Próreitoria de Extensão e Cultura, 2018. p.19-24. GARRETT, Jesse James. The elements of user experience: user-centered design for the web and beyond. 2. ed. New York: AIGA New Riders, 2011. 


\section{GIL, A. C. Como elaborar projetos de}

pesquisa. São Paulo: Atlas, 2009.

GURGEL, Claudio. Administração: elementos essenciais para a gestão das organizações. São Paulo: Atlas, 2009.

LUFT, Celso Pedro. Minidicionário.

20ª ed, São Paulo: Ática, 2001.

MOZOTA, Brigitte Borja de. Gestão do

Design. São Paulo: Bookman, 2011.

SILVA, Julia Lima da. Gestor Júnior: Plataforma de Gestão de projetos criada para a Designeria Empresa Júnior. Trabalho de Conclusão de Curso (Graduação) - Design Digital. Universidade Federal de Pelotas. Pelotas, 2019.

SURIZ, Anna Laux; SILVA, Mariana Couto; NEVES, Helena de Araujo. Designeria Empresa Júnior: projetos de design para a comunidade interna e externa à UFPel. In: CONGRESSO DE EXTENSÃO E CULTURA DA UFPEL, 3., Pelotas, 24 2016. Anais... Pelotas: Pró-reitoria de Extensão e Cultura, 2016. p.21. 